\title{
Aortic Augmentation Index
}

National Cancer Institute

\section{Source}

National Cancer Institute. Aortic Augmentation Index. NCI Thesaurus. Code C122038.

A complex measure of wave reflection calculated as the ratio of aortic augmentation pressure to pulse pressure, and used as an indirect measure of arterial stiffness. 